\title{
Notes
}

\section{First Record of the Deepwater Sculpin, Myoxocephalus thompsonii, from George Lake in Whiteshell Provincial Park, Manitoba}

\author{
L. MurRAY ${ }^{1}$, M. H. PAPST ${ }^{2}$, and J. D. ReIST ${ }^{2}$
}

${ }^{1}$ Department of Zoology, University of Manitoba, Winnipeg, Manitoba R3T 2N2 Canada

${ }^{2}$ Freshwater Institute, Department of Fisheries and Oceans, 501 University Crescent, Winnipeg, Manitoba R3T 2N6 Canada

Murray, L., M. H. Papst, and J. D. Reist. 2003. First record of the Deepwater Sculpin, Myoxocephalus thompsonii, from George Lake in Whiteshell Provincial Park, Manitoba. Canadian Field-Naturalist 117(4): 642-644.

Two adult female specimens of Deepwater Sculpin, Myoxocephalus thompsonii, were collected by gillnet from George Lake near Point Du Bois, Manitoba, 36.8 km east of Lac Du Bonnet on 21 September 2000. This constitutes the first confirmed occurrence of the species in George Lake. The only other Manitoba lakes with known populations of Deepwater Sculpin are Lake Athapapuskow and West Hawk Lake. Deepwater Sculpins have also been collected from Reindeer Lake; however, these individuals were collected from the deeper Saskatchewan side of the lake.

Key Words: Deepwater Sculpin, Myoxocephalus thompsonii, George Lake, Manitoba.

Two adult Deepwater Sculpins (Myoxocephalus thompsonii) were collected by gillnet in the deepest region of George Lake, Manitoba $\left(50^{\circ} 15.855^{\prime} \mathrm{N}\right.$, $\left.95^{\circ} 28.521^{\prime} \mathrm{W}\right)$ on 21 September 2000. One Lake Whitefish (Coregonus clupeaformis), seven Lake Trout (Sal- velinus namaycush) and 74 Shortjaw Cisco (Coregonus zenithicus) were captured in the same net as the two sculpins.

The collection site consisted of the deep basin at the north end of the lake (Figure 1). The net was set at

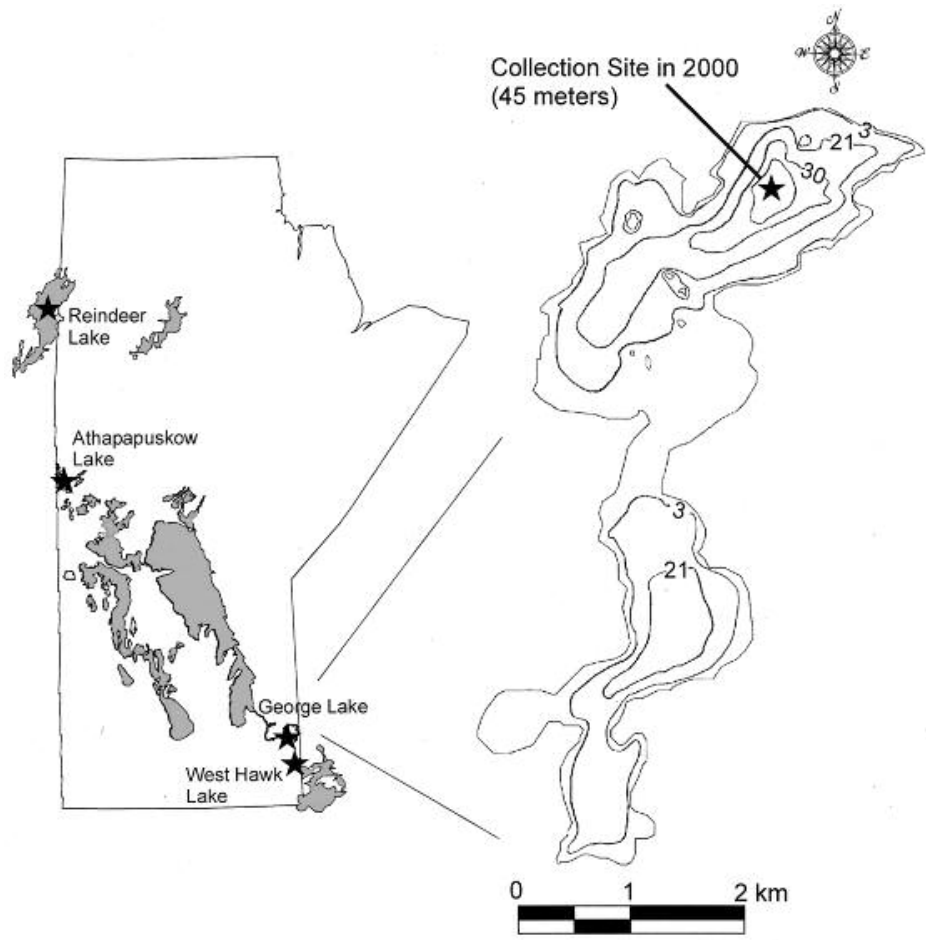

FIGURE 1. Deepwater Sculpin (Myoxocephalus thompsonii) distribution in Manitoba and adjacent Saskatchewan including the George Lake collection site (depth in meters). 


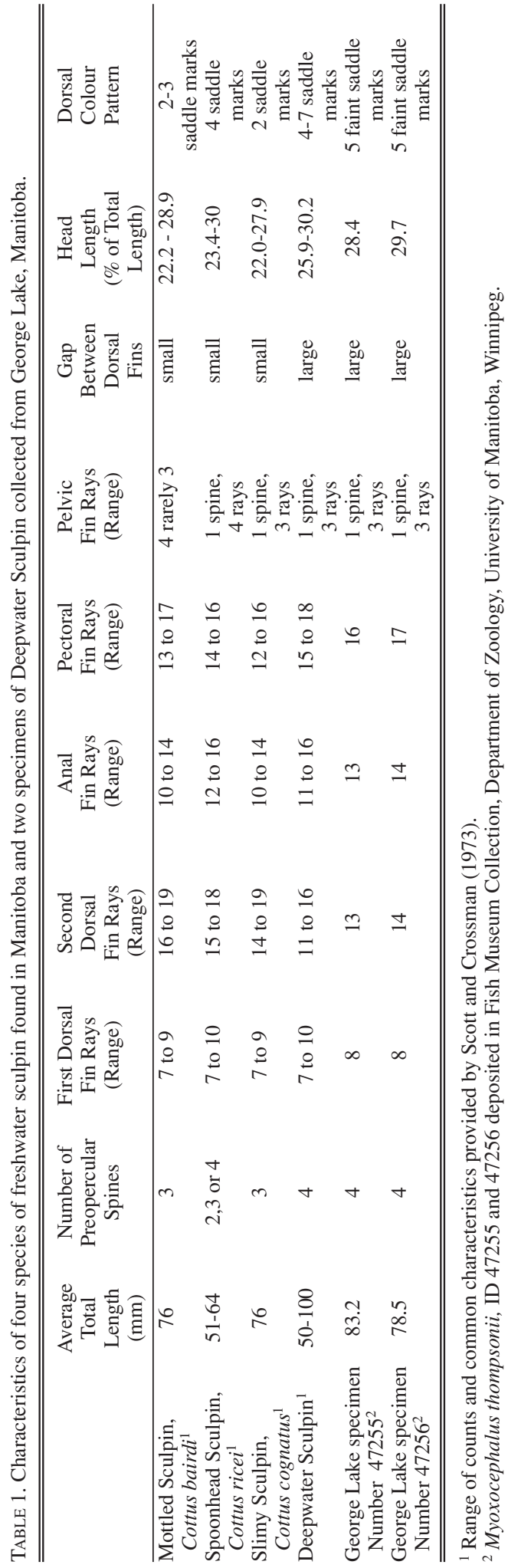

approximately $45 \mathrm{~m}$ in depth over a mud bottom. The net was $120 \mathrm{~m}$ in length and $1.83 \mathrm{~m}$ deep with $20 \mathrm{~m}$ panels ranging in mesh size from 10 to $25 \mathrm{~mm}$. The two Deepwater Sculpins were caught in the $10 \mathrm{~mm}$ mesh panel after a 14.75 -hour overnight set. The previous maximum recorded depth for the lake was $38.7 \mathrm{~m}$ and the mean depth was $11.9 \mathrm{~m}$ (Gibson and Johnson $\left.1969^{*}\right)$. The deep north basin is approximately 0.125 $\mathrm{km}^{2}$ in area with gradually sloping north and south sides and steep sloping east and west sides. Deepwater Sculpins are commonly found at a depth of $73 \mathrm{~m}$ or greater in the Great Lakes; however, there are reports of their collection at $44 \mathrm{~m}$ from Lake Michigan (Scott and Crossman 1973).

The two sculpins were tentatively identified in the field as Deepwater Sculpins based on having four preopercular spines. The specimens were placed on ice for travel and frozen once in Winnipeg. A key and descriptions of the sculpins of North America from Scott and Crossman (1973) were used to confirm the identifications of the thawed specimens. The two specimens had the margin of their gill membranes free of the isthmus, four preopercular spines of which the upper two were directed backwards and the lower two downwards, and two dorsal fins separated by a distinct gap; all characters diagnostic of Deepwater Sculpins but absent in other sculpins found in Manitoba (Scott and Crossman 1973). All characteristics of the two George Lake specimens were in the limits of variation for Deepwater Sculpins (Table 1). Two characteristics, number of preopercular spines and the gap between dorsal fins, differentiated these fish from all other possible sculpin species known from Manitoba.

The Deepwater Sculpin and the marine Fourhorn Sculpin (Myoxocephalus quadricornis) have been the focus of several taxonomic studies. McAllister (1961) considered the two taxa to be distinct species. Hubbs and Lagler (1964) proposed a subspecific designation for the North American freshwater form of Deepwater Sculpin, referring to it as Myoxocephalus quadricornis thompsonii. The subspecific designation was accepted by Bailey et al. (1970) and McPhail and Lindsey (1970). The issue was revisited by McAllister and Aniskowicz in 1976 and McAllister et al. in 1978 and based on differences between morphological characters the two forms were again considered to be distinct species. The common name (Deepwater Sculpin) and the scientific name (Myoxocephalus thompsonii) were accepted by the American Fisheries Society in 1991 (Robins et al. 1991).

Deepwater Sculpins are distributed in lakes from southwestern Quebec, through the Great Lakes region to Manitoba, northern Saskatchewan, and north to Great Slave and Great Bear lakes in the Northwest Territories (Parker 1988). An isolated population was also reported from southern Alberta (McAllister and Wells 1980). Deepwater Sculpins have previously been identified from West Hawk Lake, and Lake Athapapuskow in Manitoba and from the Saskatchewan side of Reindeer 
Lake, commonly being found in the stomachs of Lake Trout and Burbot (Lota lota) [K. W. Stewart, University of Manitoba, Department of Zoology, personal communication]. In 1969 a single sculpin was found in the stomach of a Lake Trout caught from George Lake, Manitoba. However, the specimen was not identified to species and was not kept for future examination (Gibson and Johnson 1969*). Our report confirms the presence of the Deepwater Sculpin in George Lake, Manitoba. Furthermore, this species may be found in other small lakes throughout its range provided they are of suitable depth (e.g., $>45 \mathrm{~m}$ ) for this species to inhabit. The specimens were deposited in the University of Manitoba, Zoology Department, fish museum collection.

A new record of Deepwater Sculpin is important because it adds to our limited knowledge about the distribution of this species. This lack of information is partly due to the difficulty associated with collecting this species because of the specialized gear that is required and their preference towards deepwater habitat. Because of this and their disjunct distribution, the greater number of recorded occurrences we have will help us to better understand the reasons for their current distribution. This information may also be useful to glaciologists studying the previous locations of glacial lakes by examining the current distributions of glacial relict species such as sculpins.

\section{Acknowledgments}

We thank K. W. Stewart for confirmation of our identification and further information on the distribution of Deepwater Sculpins in Manitoba. Nathan Lovejoy provided space for these specimens in the University of Manitoba, Zoology Department fish museum collection. We also thank the two anonymous reviewers of this paper for their suggestions.

\section{Documents Cited}

Gibson, R. J., and L. J. Johnson. 1969. A limnological investigation of George Lake (Whiteshell Provincial Park) in 1967. Manitoba Department of Mines and Natural Res- ources, Fisheries Branch, Manuscript Report 69-3. 48 pages.

\section{Literature Cited}

Bailey, Reeve M., J. E. Fitch, E. S. Herald, E. A. Lachner, C. C. Lindsey, C. R. Robins, and W. B. Scott. 1970. A list of common and scientific names of fishes from the United States and Canada. American Fisheries Society Special Publication. 1970: 6.

Hubbs, C. L., and K. F. Lagler. 1964. Fishes of the Great Lakes region. University of Michigan Press, Ann Arbor, Michigan. 213 pages.

McAllister, D. E. 1961. The origin and status of the deepwater sculpin, Myoxocephalus thompsonii, a Nearctic glacial relict. Bulletin of the National Museum of Canada (Contributions to Zoology 1959) 172: 44-65.

McAllister, D. E., and J. Aniskowicz. 1976. Vertebral number in North American Sculpins of the Myoxocpehalus quadricornis-Complex. Journal of the Fisheries Research Board of Canada 33: 2792-2799.

McAllister, D. E., and L. Wells. 1980. Myoxocephalus thompsoni (Girard). Page 827 in Atlas of North American freshwater fishes. Edited by D. S. Lee, C. R. Gilbert, C. H. Hocutt, R. E. Jenkins, D. E. McAllister, and J. R. Stauffer Jr. North Carolina State Museum of Natural History, Biological Survey Publication. 1980-12. 854 pages.

McAllister, D. E., R. Murphy, and J. Morrison. 1978. The complete minicomputer cataloguing and research system for a museum. Curator 21: 63-92.

McPhail, J. D., and C. C. Lindsey. 1970. Freshwater fishes of northwestern Canada and Alaska. Fisheries Research Board of Canada Bulletin 173. 381 pages.

Parker, B. J. 1988. Status of the Deepwater Sculpin, Myoxocephalus thompsoni, in Canada. Canadian Field-Naturalist 102: 126-131.

Robins, C. R., R. M. Bailey, C. E. Bond, J. R. Brooker, E. A. Lachner, R. N. Lea, and B. Scott. 1991. Common and scientific names of fishes from the United States and Canada. American Fisheries Society Special Publication 20: 1-183.

Scott, W. B., and E. J. Crossman. 1973. Freshwater fishes of Canada. Fisheries Research Board of Canada, Bulletin 184. 966 pages.

Received 2 May 2001

Accepted 26 April 2004 